\title{
Effects of early life exposure to ultraviolet C radiation on mitochondrial DNA content, transcription, ATP production, and oxygen consumption in developing Caenorhabditis elegans
}

Maxwell CK Leung ${ }^{1,2}$, John P Rooney ${ }^{1,2}$, lan T Ryde ${ }^{1}$, Autumn J Bernal ${ }^{2}$, Amanda S Bess ${ }^{1,2}$, Tracey L Crocker ${ }^{1}$, Alex Q ji ${ }^{1}$ and Joel N Meyer ${ }^{1,2^{*}}$

\begin{abstract}
Background: Mitochondrial DNA (mtDNA) is present in multiple copies per cell and undergoes dramatic amplification during development. The impacts of mtDNA damage incurred early in development are not well understood, especially in the case of types of mtDNA damage that are irreparable, such as ultraviolet $C$ radiation (UVC)-induced photodimers.

Methods: We exposed first larval stage nematodes to UVC using a protocol that results in accumulated mtDNA damage but permits nuclear DNA (nDNA) repair. We then measured the transcriptional response, as well as oxygen consumption, ATP levels, and mtDNA copy number through adulthood.

Results: Although the mtDNA damage persisted to the fourth larval stage, we observed only a relatively minor $\sim 40 \%$ decrease in mtDNA copy number. Transcriptomic analysis suggested an inhibition of aerobic metabolism and developmental processes; mRNA levels for mtDNA-encoded genes were reduced $\sim 50 \%$ at 3 hours post-treatment, but recovered and, in some cases, were upregulated at 24 and 48 hours post-exposure. The mtDNA polymerase $\gamma$ was also induced $\sim 8$-fold at 48 hours post-exposure. Moreover, ATP levels and oxygen consumption were reduced in response to UVC exposure, with marked reductions of $\sim 50 \%$ at the later larval stages.
\end{abstract}

Conclusions: These results support the hypothesis that early life exposure to mitochondrial genotoxicants could result in mitochondrial dysfunction at later stages of life, thereby highlighting the potential health hazards of time-delayed effects of these genotoxicants in the environment.

Keywords: Caenorhabditis elegans, Mitochondrial DNA damage, Mitochondrial dysfunction, Ultraviolet C radiation, Early life exposure, Genotoxicity

\footnotetext{
* Correspondence: joel.meyer@duke.edu

${ }^{1}$ Nicholas School of the Environment, Duke University, Durham, NC, USA

${ }^{2}$ Integrated Toxicology and Environmental Health Program, Duke University, Durham, NC, USA
}

\section{Biomed Central}

(c) 2013 Leung et al.; licensee BioMed Central Ltd. This is an Open Access article distributed under the terms of the Creative Commons Attribution License (http://creativecommons.org/licenses/by/2.0), which permits unrestricted use, distribution, and reproduction in any medium, provided the original work is properly cited. 


\section{Background}

In recent years, potential environmental effects on mitochondrial biology have attracted increasing research interest $[1,2]$. Mitochondrial DNA (mtDNA) is more sensitive than nuclear DNA (nDNA) to exposure to some chemicals, perhaps due to the absence of chromatin packing and many DNA repair pathways in mitochondria [3]. The high lipid content of the mitochondrial membranes and the slightly negative charge of the mitochondrial matrix also attract lipophilic or positively charged compounds to mitochondria [4]. Furthermore, non-genotoxic mitochondrial toxicants might disrupt mitochondrial function and indirectly cause mtDNA damage via generation of reactive oxygen species [5].

Theoretical considerations and some empirical data suggest that mtDNA damage that occurs at different stages of human life may lead to very different physiological effects. Since the quality of mitochondria in differentiated tissues depends on the quality of mitochondria in their precursors, mitochondrial damage in the early stages of human development may potentially affect mature tissue function. For example, mitochondrial toxicities exerted by developmental exposure to anti-HIV drugs in humans and laboratory models [6] demonstrate the importance of normal mtDNA biology during development.

The mitochondrial biology of Caenorhabditis elegans is generally similar to that of humans [7]. The genome is 13,794 base pairs in length (Additional file 1: Figure S1), compared to 16,649 in humans. The genes encoded appear to be identical; while an atp- 8 gene has not been definitively identified in C. elegans, it is probably present with an unusual sequence, as is the case in other nematodes [8]. There are also indications that the developmental biology of mitochondria is similar in C. elegans and humans: C. elegans $[7,9,10]$, like humans [11,12], shows a large increase in mtDNA copy number with age as well as a switch from anaerobic to aerobic metabolism during development. Thus, C. elegans offers a useful model for the in vivo study of mitochondrial biology, as well as the response to toxicants [13].

Recent work by Furda et al. [14] demonstrated that persistent mtDNA damage can lead to mitochondrial dysfunction, but the response was dependent on the type of DNA damage incurred. We recently described a serial ultraviolet $\mathrm{C}$ radiation (UVC) exposure protocol that resulted in a large amount of irreparable mtDNA damage in C. elegans, but permitted the repair of the nDNA damage [15]. UVC creates photodimers almost exclusively, and previous in vitro evidence $[16,17]$ suggests that such damage might inhibit mtDNA replication and transcription in vivo. In this work, we investigated the hypothesis that early life exposure to serial UVC results in later life mitochondrial dysfunction.

\section{Methods}

\section{C. elegans culture and exposures}

C. elegans were cultured and exposed to UVC during the L1 stage, largely as previously described [15]. Briefly, synchronized L1 larvae were produced by overnight hatch in M9 medium following bleach-sodium hydroxide isolation of eggs as previously described [18]. The L1 larvae were placed on peptone-free (to prevent inadvertent $\mathrm{mi}-$ crobial growth) $\mathrm{K}$ agar plates with or without $5 \mu \mathrm{g} / \mathrm{mL}$ ethidium bromide $(\mathrm{EtBr})$ for $48 \mathrm{~h}$ without food at $20^{\circ} \mathrm{C}$. Half of the plates were also exposed to $7.5 \mathrm{~J} / \mathrm{m}^{2} \mathrm{UVC}$ radiation at 0,24 , and $48 \mathrm{~h}$ as described [15], and then transferred to OP50-seeded plates. The UVC exposure protocol is based on the fact that UVC-induced DNA damage is quickly repaired in the nuclear but not mitochondrial genome [15,19], thus allowing for accumulation of mitochondrial DNA damage while permitting repair of nuclear DNA. This protocol results in no larval growth delay prior to the L4 stage [15]. The transgenic strain PE255 expressing firefly luciferase as an in vivo reporter for ATP level [20] was generously provided by Dr. Cristina Lagido (University of Aberdeen, UK). The wildtype strain N2 was obtained from Caenorhabditis Genetics Center (University of Minnesota), which is funded by the NIH National Center for Research Resources (NCRR).

\section{Microarray experiments}

$\mathrm{N} 2$ nematodes were sampled for RNA isolation at $3 \mathrm{~h}$ after the first UVC exposure, $1 \mathrm{~h}$ prior to the second exposure, $1 \mathrm{~h}$ prior to the third exposure, and $3 \mathrm{~h}$ after the third exposure, and transferred to OP50 plates (schematic presented in Figure 1). Transfer to OP50 plates and isolation for freezing were accomplished by washing nematodes off of plates into a $15 \mathrm{~mL}$ tube with $\mathrm{K}$-medium, pelleting by centrifugation, followed by two additional cycles of resuspension and centrifugation as described [19]. Nematodes were frozen by dripping 3,000-5,000 pelleted nematodes suspended in about $500 \mu \mathrm{K}$-medium into liquid nitrogen, and stored at $-80^{\circ} \mathrm{C}$. The pellets were ground into fine powder with a liquid nitrogen-cooled mortar and pestle and RNA was extracted using an RNeasy kit (Qiagen, Valencia, CA, USA). RNA was quantified with a NanoDrop 8000 spectrophotometer (Thermo Scientific/NanoDrop, Wilmington, DE, USA) and analyzed for integrity with an Agilent 2100 BioAnalyzer G2939A (Agilent Technologies, Santa Clara, CA, USA). These exposures were carried out seven times. The seven replicates generated a total " $n$ " of between 4 and 6 for each treatment and timepoint, after excluding samples lost due to insufficient mRNA quality or principle components analysis-based identification of outliers.

Gene expression analysis was conducted using Affymetrix /C. elegans/ GeneChip ${ }^{\circledR}$ arrays (Affymetrix, Santa Clara, CA). Hybridization targets were prepared with 


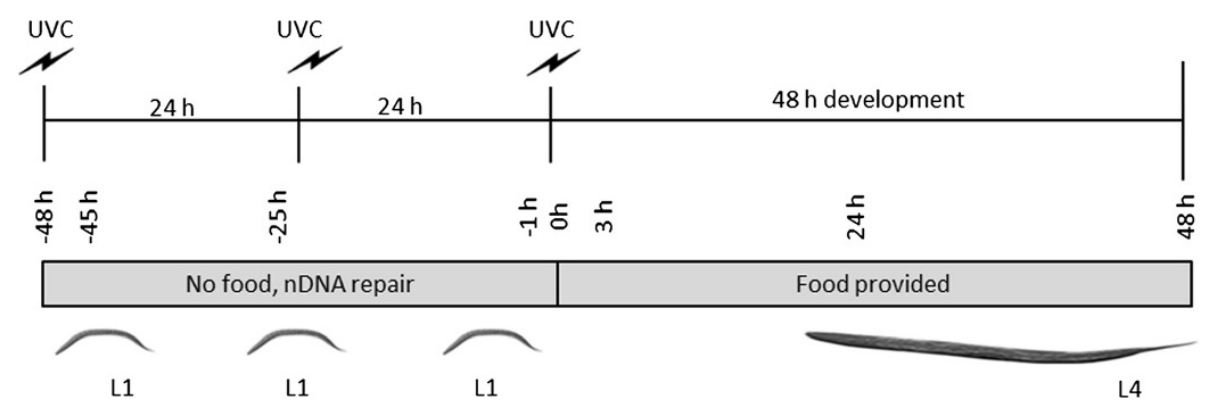

Figure 1 Experimental design. Liquid-hatched L1 stage C. elegans were exposed to $7.5 \mathrm{~J} / \mathrm{m}^{2}$ UVC over $48 \mathrm{~h}$, in the absence of food, permitting nDNA repair but accumulation of mtDNA damage [15]. Nematodes were then placed on food plates and followed for another $48 \mathrm{~h}$. We measured mRNA levels, genome copy number, DNA damage, ATP levels, and oxygen consumption at multiple times during and after the UVC exposures. All times are given relative to the final dose and transferral to food $\left(={ }^{~ " 0 ~} \mathrm{~h}\right.$ "). For example, mRNA sampled immediately prior to the second dose of UVC would be described as sampled at "- 25 h", and " $3 \mathrm{~h}$ " if it were sampled $3 \mathrm{~h}$ after the final UVC exposure. Representative examples are presented to orient the reader.

MessageAmp $^{\mathrm{TM}}$ Premier RNA Amplification Kit (Applied Biosystems/Ambion, Austin, TX) from total RNA, hybridized to GeneChip ${ }^{\circledR}$ C. elegans Genome Arrays in Affymetrix GeneChip ${ }^{\circledR}$ hybridization oven 645 , washed in Affymetrix GeneChip ${ }^{\circledR}$ Fluidics Station 450 and scanned with Affymetrix GeneChip ${ }^{\circledR}$ Scanner $7 \mathrm{G}$ according to standard Affymetrix GeneChip ${ }^{\circledR}$ Hybridization, Wash, and Stain protocols (Affymetrix, Santa Clara,CA). Microarray data have been deposited in the National Center for Biotechnology Information's GEO and are accessible through GEO series accession number GSE38997.

\section{Microarray data preprocessing, normalization, error modeling, and initial visualization}

We used Principal Components Analysis (PCA) followed by pairwise correlation analysis on unfiltered data to identify outlier samples. Data preprocessing, normalization, and error modeling were performed with Rosetta Resolver ${ }^{\circledR}$ after grouping biological replicates. The resulting foldchanges and $\mathrm{p}$-values were used for Cytoscape analyses (described below).

\section{GeneSpring-based analysis of microarray data}

We used GeneSpring version GX11 (Agilent) to carry out ANOVA, PCA analysis, gene ontology (GO) enrichment analysis, and some visualization.

\section{Interactome-based analysis of microarray data}

Cytoscape (version 2.8.2) was used to overlay microarray data onto two interactomes: the high-confidence WI8 interactome compiled by the Vidal lab [21], and an interactome built by joining four previously-described interactomes: the integrated_function_network from the Vidal lab [21]; an interactome that we assembled previously [19] based on the BIND database [22] and Zhong and Sternberg [23] interactome; the "core" interactome described by Lee et al. [24]; and the higher-probability interactome generated by Alexeyenko and Sonnhammer [25] using a probability of functional coupling cut-off of 0.75 . These networks are referred to herein as "WI8" and "Union4" and are composed of 2500 nodes and 3706 edges, and 14334 nodes and 346484 edges, respectively. The Union4 interactome is presented as Additional file 2 in .sif format. jActiveModules (version 2.23, [26]) was used to find, via greedy searching, the top 10 modules with a maximum overlap of 0.3 , as identified at a search depth of 1 and maximum depth from start nodes of 2 (with the WI8 interactome) or 1 (with the Union4 interactome). The resulting subnetworks were analyzed for Gene Ontology enrichment with the BiNGO (version 2.44) plugin [27]. We assessed overrepresentation using the hypergeometric test with the Benjamini and Hochberg False Discovery Rate multiple testing correction and significance level of 0.05 , testing each cluster versus the entire annotation and identifying altered GO Biological Processes.

\section{mtDNA and nDNA copy number measurements}

mtDNA copy number was measured in N2 and PE255 nematodes using a modification of the real-time PCR assay described by Bratic et al. [28]; this assay is based on a plasmid DNA-based standard curve and so generates actual rather than relative copy numbers. The only change to the assay was the use of 2-fold rather than 10 -fold dilutions in the standard curve. nDNA copy number was measured using primers designed with Primer 3 [29]: forward - 5'-GCC GAC TGG AAG AAC TTG TC-3'; reverse - 5'-GCG GAG ATC ACC TTC CAG TA-3'. These primers amplify a 164 bp region of the gene W09C5.8 (cox-4). Nuclear copy number was determined by creating a standard curve for the nuclear DNA based on young adult (24 h post-L4) $g l p-1$ mutant nematodes raised at $25^{\circ} \mathrm{C}$. At this temperature, this strain has a fixed number of cells since it has no germline proliferation [30] and C. elegans somatic cells do not divide in 
adulthood [31]. We based the standard curve on the calculation that adults lacking germ cell proliferation would contain 3134 genomic copies [32,33]. Real-time PCR was carried out in a 7300 Real Time PCR System (Applied Biosystems), under the following conditions: $2 \mathrm{~min}$ at $50^{\circ}$ C, $10 \mathrm{~min}$ at $95^{\circ} \mathrm{C}, 40$ cycles of $15 \mathrm{sec}$ at $95^{\circ} \mathrm{C}$ and $60 \mathrm{sec}$ at $60^{\circ} \mathrm{C}$. A dissociation curve was calculated for each sample at the end of each profile. The $25 \mu \mathrm{l}$ PCR reactions contained $12.5 \mu \mathrm{l}$ of SYBR Green PCR Master Mix (Applied Biosystems), $8.5 \mu \mathrm{H} \mathrm{H}_{2} \mathrm{O}, 2 \mu \mathrm{l}$ of target-specific primers at $400 \mathrm{nM}$ final concentration, and $2 \mu \mathrm{l}$ of nematode lysate obtained as described [34]. The ABI PRISM 7300 Sequence Detection System Software, Version 1.1 (Applied Biosystems) was used to carry out data analysis. All samples were run in triplicate and triplicates were averaged prior to analysis.

\section{DNA damage measurements}

nDNA and mtDNA damage were evaluated using a QPCRbased method as previously described [35] except that mtDNA damage was normalized to mtDNA copy number based on measurements obtained using the realtime method described above.

\section{mRNA levels}

mRNA levels of five mitochondrial electron transport chain (ETC) complex subunits, including two mitochondriaencoded genes ( $c t b-1$ and $n d-5)$ and three nucleus-encoded genes (C34B2.8, D2030.4 and K09A9.5), were measured using real-time PCR. mRNA levels of the nuclear-encoded polg-1 gene, which encodes the $C$. elegans mitochondrial DNA polymerase $\gamma$, were also measured. $250 \mathrm{ng}$ of mRNA isolated from $C$. elegans as described above was converted to cDNA using the Qiagen Omniscript Reverse Transcription kit. Real time PCR was carried out with a 7300 Real Time PCR System as described above except that the extension temperatures were $62^{\circ} \mathrm{C}$ for $c t b-1$ and $n d-5$, and $60^{\circ} \mathrm{C}$ for C34B2.8, D2030.4 and K09A9.5. The average mRNA fold change of each target gene was calculated by comparing the CT (cycle threshold) of the target gene to that of the housekeeping genes $c d c-42$ and pmp-3 [36]. Primers were based on the literature (ctb-1, polg- 1 , and $n d-5$ from [28]) except that we used an annealing temperature of $62^{\circ}$ rather than $60^{\circ} \mathrm{C}$, were designed using Primer 3 , or were recommended by Dr. Marni Falk (University of Pennsylvania: C34B2.8, D2030.4 and K09A9.5). The experiment was carried out twice for a total " $n$ " of 3-5 except when the microarray samples were used in which case the "n" was 57 from 5-7 experiments. Unpublished primers were as follows: $c d c-42$, forward - 5'- GAG AAA AAT GGG TGC CTG AA-3', reverse - 5'-CTC GAG CAT TCC TGG ATC AT-3' (101 bp); pmp-3, forward - 5'- GTT CCC GTG TTC ATC ACT CAT-3, reverse - 5'- ACA CCG TCG AGA AGC TGT AGA-3' (115 bp); D2030.4, forward - 5'- GCG
AGA TGA AGG CTA CTT GG-3', reverse - 5'-GGT GCA TTT TGG GTT TGG-3' (115 bp); K09A9.5, forward - 5'AGT CAT CAT CAA GGC CAT CC-3', reverse - 5'-TTG TTG GGA TGT CAA TAC CG-3' (185 bp); C34B2.8, forward - 5'- CTT TTC CGA AGC TTG TCT GG-3', reverse - 5'-CTT GGC CAA CAA TTT GAG C-3' (197 bp). All samples were run in duplicate or triplicate and replicates were averaged prior to analysis.

\section{ATP assay}

Steady-state ATP levels were determined by the luminescence level of the PE255 strain [20,37]. Luminescence was measured in a 96-well microplate reader (FLUOstar OPTIMA, BMG Labtech, Ortenberg, Germany) with approximately 300 nematodes per well (in $100 \mu \mathrm{l}$ ) in the visible spectral range between 300 and $600 \mathrm{~nm}$ (firefly luciferase typically emits at 550-570 nm). An automated dispenser delivered $50 \mu \mathrm{l}$ of luminescence buffer to each well, consisting of citrate phosphate buffer $\mathrm{pH} 6.5,0.1 \mathrm{mM}$ D-luciferin, $1 \%$ DMSO and $0.05 \%$ triton-X (all final concentrations). Three separate experiments with 3-5 replicates total at each timepoint were conducted.

\section{Oxygen consumption measurement}

Oxygen consumption over 2 minutes was measured in PE255 nematodes in an oxygen chamber (782 Oxygen Meter, Strathkelvin Instruments, North Lanarkshire, Scotland) as described [38]. C. elegans were washed with $\mathrm{K}$ medium and counted using a nematode sorter (COPAS, Union Biometrica, Holliston, MA). Three separate experiments with 2 replicate plates per timepoint per dose each were conducted (1-4 samples per plate were measured and averaged), resulting in a total $n=4-6$. Each replicate contained 1000 nematodes for the 0,3 , and $24 \mathrm{~h}$ time points and 500 nematodes for the $48 \mathrm{~h}$ time point.

\section{Statistical analysis}

All data except the microarray data were analyzed using Statview@ for Windows (Version 5.0.1, SAS Institute Inc., Cary, NC). "Treatment," "time," and "experiment" were treated as independent variables in two- or three-way ANOVA analyses. When warranted based on initial ANOVA analyses, posthoc comparisons were carried out using Fisher's Protected Least Significant Differences (FPLSD) test. Since oxygen consumption and ATP levels increased dramatically during larval development, and we wished to test for proportional differences based on treatment, we log-transformed those data prior to analysis. However, non-log-transformed data were plotted to avoid obscuring the large developmental changes that occurred. A p-value of less than 0.05 was considered statistically significant. Throughout the manuscript, error bars indicate the standard error of the mean. 


\section{Results}

Transcriptomic response during and $3 \mathrm{~h}$ after UVC exposures

We examined the transcriptomic response to a UVC exposure protocol that results in high levels of mtDNA damage but allows for repair of the nDNA damage that is also induced [15]. Since EtBr, a specific inhibitor of mtDNA replication [39], exacerbates the response of C. elegans to such mtDNA damage [15], we also exposed half of the nematodes to EtBr. We considered the possibility that coexposure to EtBr and UVC would lead to increased DNA damage compared to UVC alone due to photosensitization $[40,41]$; however, we did not detect any difference in DNA damage with EtBr co-exposure (Additional file 1: Figure S2). In a parallel experiment, we also measured mtDNA copy number throughout the exposure. The mtDNA copy number did not change in control nematodes, nor was there a marked change in mtDNA copy number due to UVC during the exposure (Additional file 1: Figure S2).

We sampled mRNA at 4 timepoints $(3 \mathrm{~h}$ after the first UVC exposure or "- $45 \mathrm{~h}$ "; $1 \mathrm{~h}$ prior to the second exposure or $-25 \mathrm{~h} ; 1 \mathrm{~h}$ prior to the final exposure, and $3 \mathrm{~h}$ after the final exposure and being placed on food: Figure 1). At each timepoint, nematodes were sampled that had been exposed to UVC, EtBr, both, or neither (controls). The "n" was 4-6 samples per timepoint per treatment, each generated from different experiments (separated in time).

Most differentially expressed transcripts (DETs) were associated with time. Three-factor ANOVA (time, UVC, EtBr with Benjamini-Hochberg correction) identified 10095 genes that showed differential expression over time, using a cut-off of $\mathrm{p}<0.001$ (which results in 10 differentially expressed genes expected by chance). Only 1447 DETs resulted from EtBr treatment, and 36 DETs resulted from

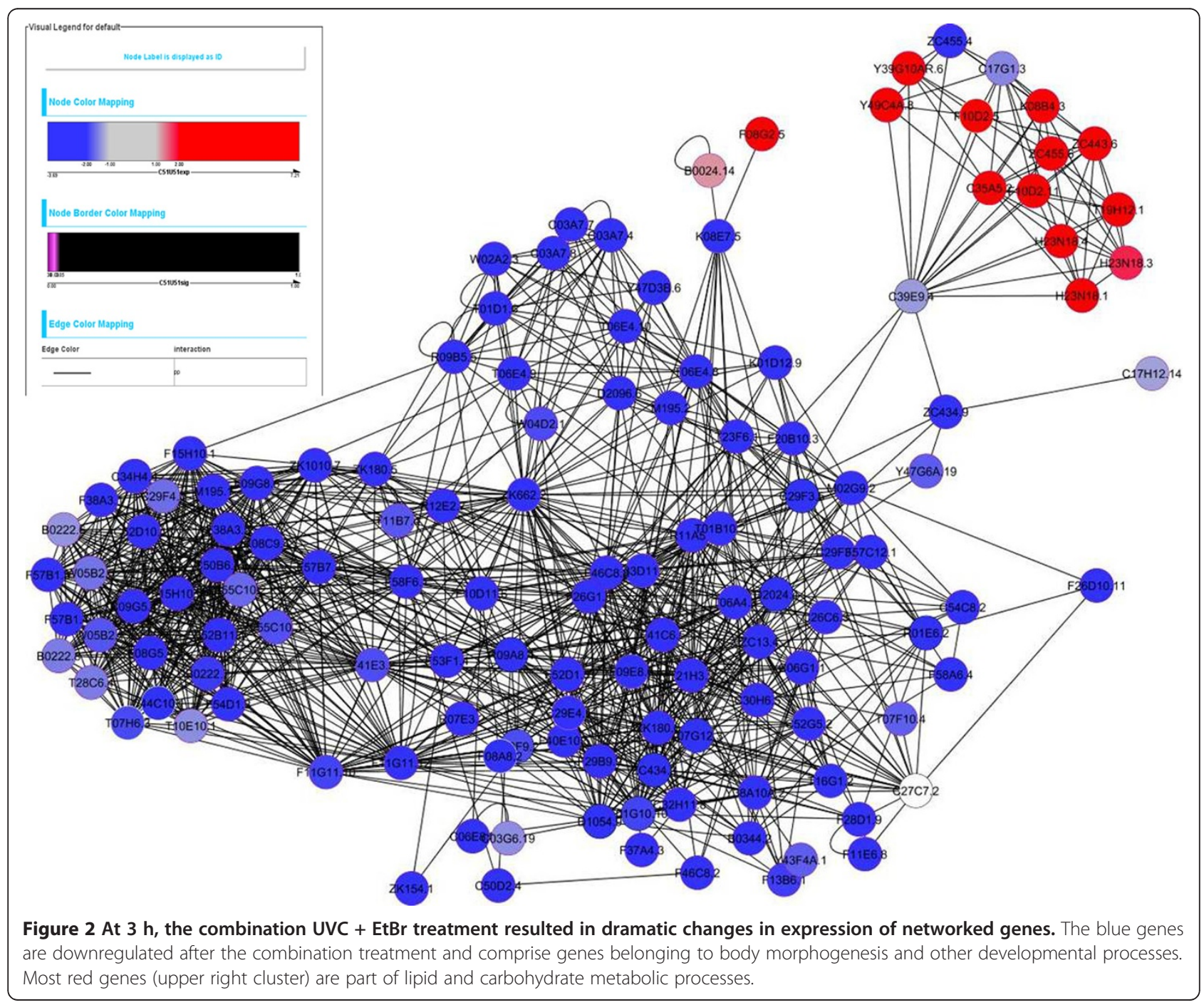


UVC. At this cut-off only three genes demonstrated altered responses to $\mathrm{EtBr}$ based on time (i.e., a time $\mathrm{x} \mathrm{EtBr}$ interaction), six genes demonstrated a time-dependent response to UVC, and no genes were identified for which the response to UVC was dependent on the presence of EtBr or $\mathrm{EtBr}$ and time. PCA results also indicated a very strong effect of time. PCA and detailed ANOVA results for the global dataset are presented in Additional file 1: Figure S3. Since we were most interested in the combined effect of prolonged inhibition of mtDNA replication and mtDNA damage, and since the presence of food is likely to alter mitochondrial function and response to stressors, we also carried out ANOVA on the $3 \mathrm{~h}$ timepoint samples only. However, we found no significant $(\mathrm{p}<0.05)$ UVC $x \mathrm{EtBr}$ interactions for any genes at $3 \mathrm{~h}$.
At $3 \mathrm{~h}$, all three treatments resulted in many DETs associated with many developmental processes. Shown in Figure 2 is one of the most altered gene networks ("neighborhoods") identified by jActiveModules at $3 \mathrm{~h}$ when comparing the combination treatment to control nematodes; BiNGO-based GO enrichment analysis identified developmental processes as a top altered process. Similar GO results were obtained using GeneSpring to characterize DETs detected by ANOVA. Furthermore, the combination treatment led to greater alterations in expression of developmental genes compared to either treatment alone (e.g., Additional file 1: Figure S4). This is consistent with our previous observation of developmental delay after both treatments, which was strongest in the combination [15].

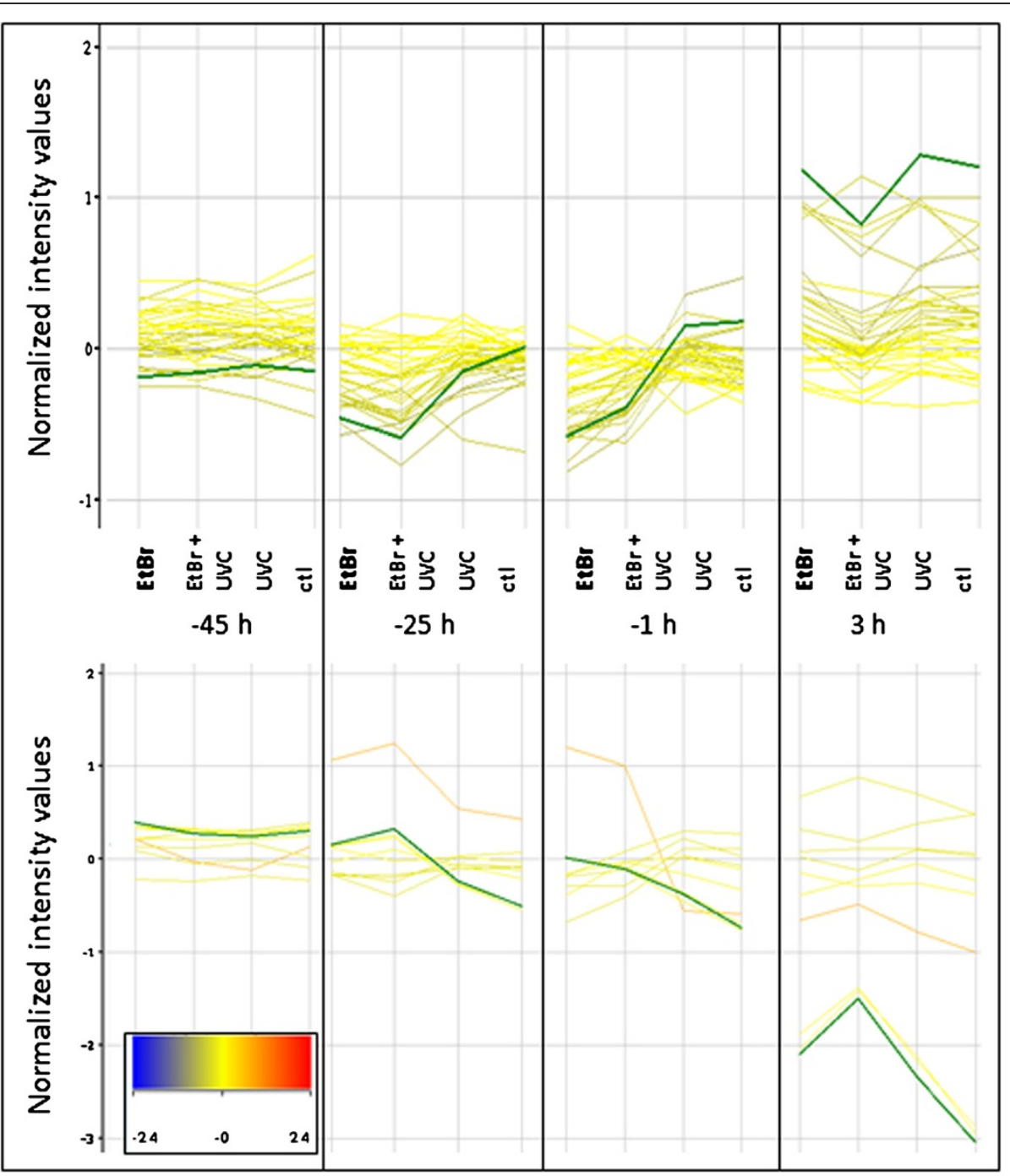

Figure $3 \mathrm{EtBr}$ and UVC exposures resulted in decreased expression of many oxidative phosphorylation genes (top panel; sucg-1 highlighted in green), but increased expression of some glyoxylate genes (bottom panel; icl-1 highlighted in green). Red-blue scale coloration is based on comparison to mRNA levels in control samples at $-45 \mathrm{~h}$. Normalized intensity values are on a binary log scale (i.e. "1" indicates a 2-fold change, "2" a 4-fold change, etc). $n=4-6$. 
We hypothesized that persistent mtDNA damage would lead to reduced (via damage-mediated inhibition of the mitochondrial RNA polymerase) or upregulated (compensatory) expression of genes coding for mitochondrial proteins, both from the mitochondrial and nuclear genomes. Using published lists of mitochondrial genes [42], we found that at timepoints later than $3 \mathrm{~h}$, some transcripts for oxidative phosphorylation decreased in the presence of $\mathrm{EtBr}$, and this effect was often exacerbated by UVC (Figure 3). Furthermore, several genes in the glyoxylate pathway were induced by EtBr and EtBr + UVC at several timepoints; many of these same transcripts were also decreased in abundance across treatments at $3 \mathrm{~h}$ (after food addition) (Figure 3). We observed no statistically significant differences in mitochondrial-encoded transcripts (not shown), but since these are poorly represented on the platform that we used, we also carried out additional real time PCR-based analyses (see below).

Based on the role of mitochondrial fusion, fission, and autophagy in responding to UVC-induced mtDNA damage [15], we examined expression specifically of genes in these pathways. We observed a small increase in expression of some autophagy genes at -25 and $-1 \mathrm{~h}$, along with an inhibition of the decrease observed in many autophagy genes at $3 \mathrm{~h}$, after food was available (Additional file 1: Figure S5). There was either no change or a small increase in fusion and fission genes after $\mathrm{EtBr}$ and $\mathrm{EtBr}+\mathrm{UVC}$, only at $3 \mathrm{~h}$ (Additional file 1: Figure S5).

While of less relevance for this manuscript, the transcriptomic responses to EtBr and UVC alone are interesting in their own right. The DETs (defined liberally as $\mathrm{p}<0.05$ and fold-change $>1.2$, based on Rosetta Resolver values) for each pairwise treatment comparison at each timepoint are provided in Additional file 3. The shortterm $(-45 \mathrm{~h})$ response was stronger in terms of number of regulated genes for UVC than $\mathrm{EtBr}$, but the reverse was true thereafter. This suggests that UVC led to a more robust signaling response, but $\mathrm{EtBr}$ altered more biological processes over time or that the response was slower due to the kinetics of uptake of EtBr. The most altered gene ontologies observed for UVC exposure were stress response and aging. EtBr treatment alone altered expression of many development-related genes (as described earlier) but also led to a dramatic induction of many xenobiotic metabolism genes, in particular cytochrome P450s (some of which were induced 50 to 100-fold: Additional file 1: Figure S6), but also including p-glycoprotein and glutathione S-transferase genes (Additional file 3). Some xenobiotic metabolism genes, however, were down-regulated by EtBr (e.g., cyp-35A3, ugt-37, and gst-25; Additional file 3). Finally, of all DNA repair genes that we identified previously [34], only one was strongly upregulated by any treatment at any time: pme-4 (Additional file 1 : Figure S7).

We next carried out additional experiments to test whether mitochondrial function was in fact altered, as suggested by the transcriptomic data, and whether the mild alterations in levels of mtDNA- and nuclear genomeencoded genes would persist to later timepoints.

\section{mtDNA damage was persistent to the L4 stage (48 $\mathrm{h}$ timepoint)}

Immediately $(0 \mathrm{~h})$ after the third UVC exposure, $2.7 \pm 0.1$ mitochondrial and $1.1 \pm 0.1$ nuclear DNA lesions per 10 kilobases were detected in larval C. elegans (Figure 4). nDNA damage dropped to $0.4 \pm 0.1$ at $3 \mathrm{~h}$ post-exposure, and to $0.0 \pm 0.1$ in $48 \mathrm{~h}$. The mtDNA lesions, in contrast, persisted at $1.8 \pm 0.2$ and $0.7 \pm 0.2$ at 3 and $48 \mathrm{~h}$, respectively. These results suggest a dilution of the UVC-induced DNA damage due to replication of the nuclear and mitochondrial genomes throughout C. elegans development, since the kinetics of photodimer removal in nuclear and mitochondrial DNA in C. elegans would not explain this rate of reduction $[15,19,34]$.

\section{Measurement of mtDNA and nDNA copy number throughout development}

We used RT-PCR to establish a baseline of mtDNA and nDNA copy number in N2 nematodes (Table 1). As previously observed [9,28], mtDNA copy number increased
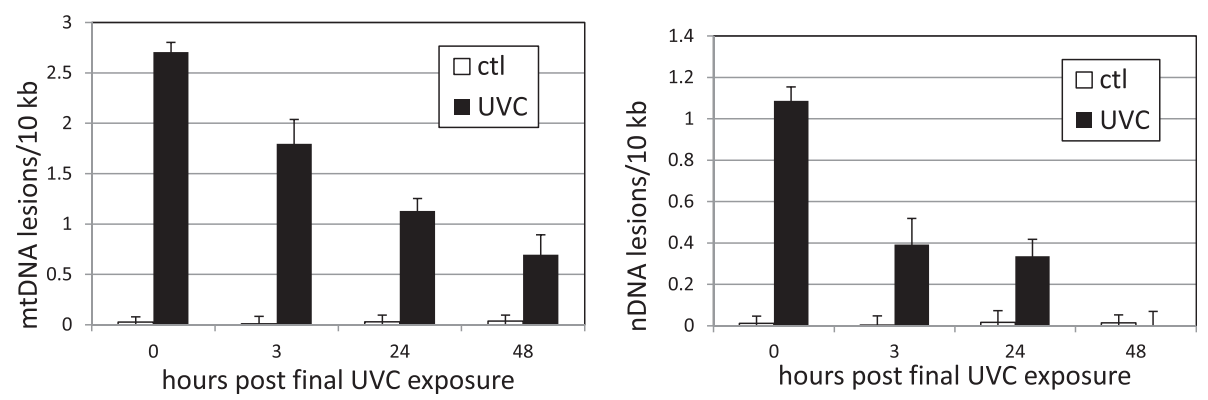

Figure 4 Exposure to UVC resulted in persistent mtDNA damage in larval C. elegans. Main effects of treatment, time, genome, and all interactions were significant ( $p \leq 0.0002$ ). At 0,3 , and $24 \mathrm{~h}$ after the last exposure, DNA damage was statistically significant in both genomes. At $48 \mathrm{~h}$, DNA damage was detected in mtDNA ( $p=0.0009)$ but not nDNA ( $p=0.82)$. Note different $y$-axis scales. $n=4-11$ in two experiments. 
Table 1 Nuclear and mitochondrial DNA copy number in wildtype (N2) C. elegans raised ay 20 C, starting from eggs laid on $\mathbf{k}$ agar plates, \pm standard error of the mean

\begin{tabular}{|c|c|c|c|}
\hline Developmental stage & nDNA copy number & mtDNA copy number $\left(\times 10^{4}\right)$ & mtDNA:nDNA ratio \\
\hline Egg, 0 h $(n=6)$ & $92 \pm 36$ & $4.12 \pm 1.30$ & $948 \pm 498$ \\
\hline Hatch, 13 h $(n=15)$ & $890 \pm 23$ & $6.26 \pm 0.16$ & $71 \pm 3$ \\
\hline Mid-L1, 21 h $(n=7)$ & $1155 \pm 57$ & $9.96 \pm 0.58$ & $87 \pm 4$ \\
\hline Mid-L2, 33.5 h $(n=7)$ & $1492 \pm 119$ & $14.00 \pm 1.45$ & $94 \pm 7$ \\
\hline$L 2 / L 3,38 h(n=8)$ & $2000 \pm 140$ & $20.17 \pm 1.77$ & $101 \pm 4$ \\
\hline Early $L 3,41 \mathrm{~h}(\mathrm{n}=8)$ & $2856 \pm 235$ & $29.23 \pm 2.72$ & $103 \pm 5$ \\
\hline Late $L 3,44$ h $(n=8)$ & $3242 \pm 245$ & $38.63 \pm 3.18$ & $119 \pm 6$ \\
\hline$L 3 / L 4,47$ h $(n=7)$ & $3967 \pm 273$ & $48.39 \pm 3.55$ & $123 \pm 6$ \\
\hline Early $L 4,50.7$ h $(n=8)$ & $4805 \pm 205$ & $56.12 \pm 4.02$ & $116 \pm 5$ \\
\hline Late $L 4,54.3(n=12)$ & $5552 \pm 325$ & $73.99 \pm 7.43$ & $131 \pm 7$ \\
\hline L4/young adult, $58 \mathrm{~h}(\mathrm{n}=10)$ & $6496 \pm 228$ & $102.77 \pm 4.81$ & $159 \pm 8$ \\
\hline Early young adult, $66 \mathrm{~h}(\mathrm{n}=12)$ & $7430 \pm 550$ & $126.49 \pm 12.18$ & $174 \pm 13$ \\
\hline Late young adult, $66 \mathrm{~h}(\mathrm{n}=11)$ & $7737 \pm 310$ & $123.57 \pm 12.15$ & $157 \pm 12$ \\
\hline Adult, $70 \mathrm{~h}(\mathrm{n}=12)$ & $9456 \pm 315$ & $140.72 \pm 6.10$ & $152 \pm 10$ \\
\hline
\end{tabular}

" $0 \mathrm{~h}$ " refers to eggs laid within a $1 \mathrm{~h}$ period and immediately collected frozen. " $\mathrm{n}$ " indicates the number of individual eggs or nematodes lysed and separately analyzed.

significantly late in development. In contrast to those previous reports, we saw only a slight increase in mtDNA copy number in early larval stages that did not keep pace with nDNA replication, resulting in a $>10$-fold decrease in mtDNA:nDNA ratio from freshly laid eggs to hatched L1s. This ratio then roughly doubled by adulthood. These studies were performed on eggs laid on plates during $1 \mathrm{~h}$, so that " $0 \mathrm{~h}$ " refers to eggs frozen within $1 \mathrm{~h}$ of being laid. Since our subsequent experiments were carried out on nematodes that were raised from eggs that were agesynchronized via bleach-sodium hydroxide isolation of eggs and liquid hatch, we also compared mtDNA copy number after one or two days without food in M9 medium (comparable to the conditions used for the serial UVC exposure). The egg prep resulted in a decrease of $~ 50 \%$ in mtDNA copy number in the growth-arrested L1s, but copy number returned to normal by the L3 stage (data not shown; also compare Table 1 with Additional file 1: Figure S2).

\section{UVC exposure affected mtDNA copy number but not nDNA copy number}

Because somatic cell division and development are invariant in C. elegans [31], nDNA copy number serves as a proxy for developmental stage. Despite the developmentrelated transcriptomic responses we observed and the mild developmental delay that we previously documented at this dose of serial UVC [15], we did not detect a reduction in nDNA copy number during this experiment ( $\mathrm{p}=0.82$ for main effect of treatment, $\mathrm{p}<0.0001$ for main effect of time; $\mathrm{p}=0.37$ for interaction; Figure 5).

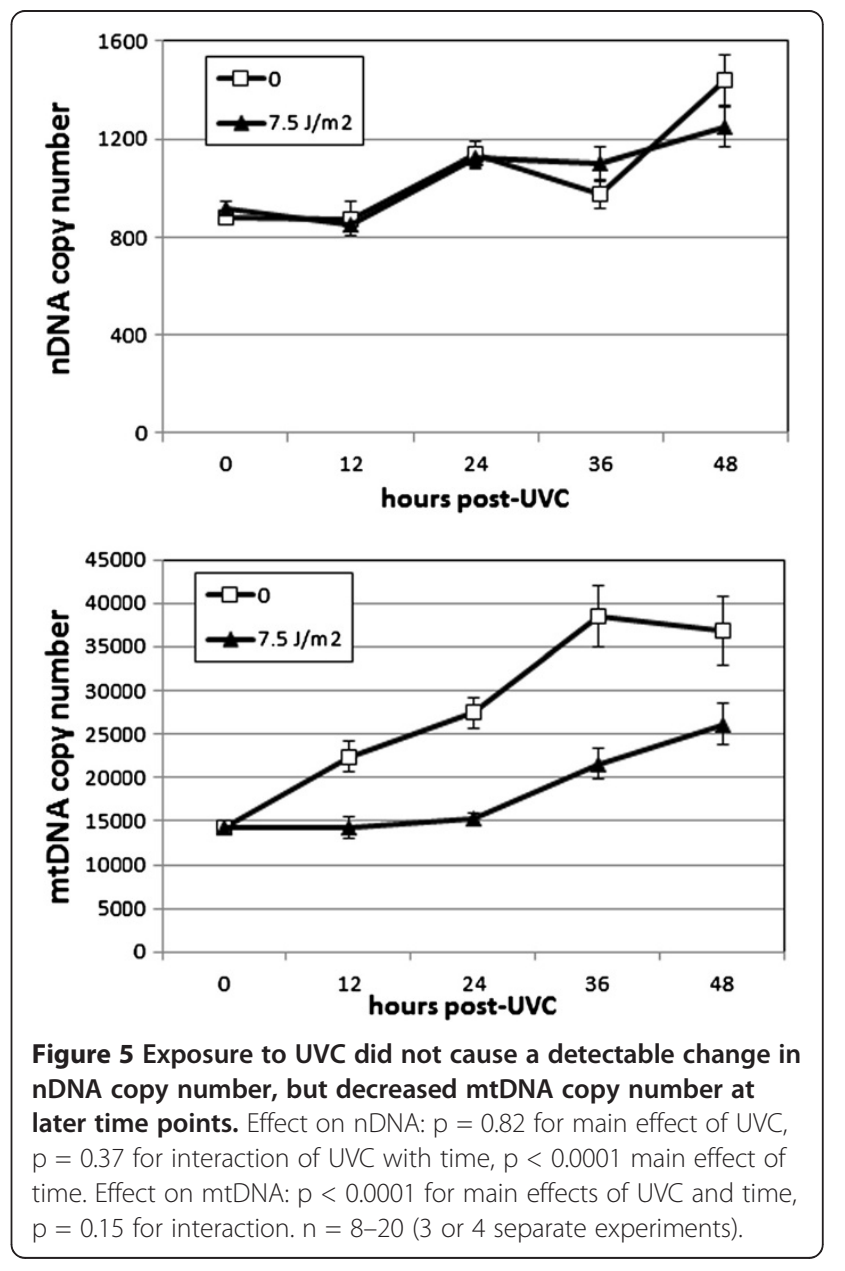


Nonetheless, preliminary experiments suggested that adult egg reproduction (i.e., at later timepoints) was affected by the UVC treatment.

In contrast, and as hypothesized based on the in vitro ability of UVC-induced photodimers to inhibit DNA polymerase $\gamma$ [16], mtDNA copy number was decreased at all later timepoints $(\mathrm{p}<0.0001$ for main effects of time and treatment; $\mathrm{p}=0.048$ for interaction; timepoints past $0 \mathrm{~h} \mathrm{p}<0.05$ UVC vs control by FPLSD; Figure 5).

These experiments were carried out in the PE255 strain, in order to permit comparison to the ATP data derived from that strain (see below). However, we observed similar results (no effect on nDNA copy number, decreased mtDNA copy number) in preliminary experiments with $\mathrm{N} 2$ and $g l p-1$ strains as well (data not shown).

\section{UVC exposure altered expression of mtDNA- and nDNA-encoded mRNAs}

We also hypothesized that UVC-induced mtDNA damage would inhibit the mitochondrial RNA polymerase [17], resulting in a decrease in mtRNAs. Because our microarray platform has few probes for mtDNA-encoded genes, we examined those samples using RT-PCR analysis. At $3 \mathrm{~h}$, but not earlier, mRNA levels for the mtDNA-encoded genes $c t b-1$ and $n d-5$ were decreased $\sim 50 \%$ after exposure to UVC or UV + EtBr, without a change in mRNA levels for 4 nDNA-encoded mRNAs (C34B2.8, D2030.4 and K09A9.5, coding for ETC (Complex I) components, and polg-1, coding for the mitochondrial DNA polymerase $\gamma$ ) (Additional file 1: Figure S8). However, formal statistical comparisons of each gene at each timepoint could not be carried out due to the lack of a significant time $\mathrm{x}$ treatment $x$ gene interaction.

Next, to determine whether this change was persistent through development, we repeated the experiments and measured mRNA levels for the same genes at $0,3,12$, 24 , and $48 \mathrm{~h}$ post-exposure. We observed lower amounts of the mtDNA-encoded mRNAs at 0-12 h (Figure 6). However, we also detected a significant increase in mRNA levels for all of the examined transcripts at 24 and $48 \mathrm{~h}$, including an 8-fold induction of polg-1 at $48 \mathrm{~h}$ postexposure (Figure 6). Finally, we replicated this experiment in the PE255 strain, with somewhat different results. In the PE255 nematodes, the mtDNA and most nDNAencoded ETC component mRNAs were generally lower at nearly all timepoints after UVC; only polg- 1 was induced, but to a lesser extent than in the N2 nematodes (Additional file 1: Figure S9).

\section{UVC exposure resulted in a delayed decrease in steady-state ATP level}

To test if altered mtDNA and mtRNA levels were associated with altered mitochondrial energy production, we measured ATP levels in vivo using a well-validated [20,43] transgenic strain expressing a luciferase gene. ATP levels were similar in control and UVC-exposed nematodes until $\sim 24 \mathrm{~h}$ after the UVC exposure, despite a $\sim 50 \%$ drop in the $3 \mathrm{~h}$ after the nematodes were plated on food plates (Figure 7). As observed previously using traditional methods for ATP analysis [44], ATP levels increased significantly during larval development. The UVC treatment resulted in a $\sim 50 \%$ decrease in ATP levels at 24,36 , and
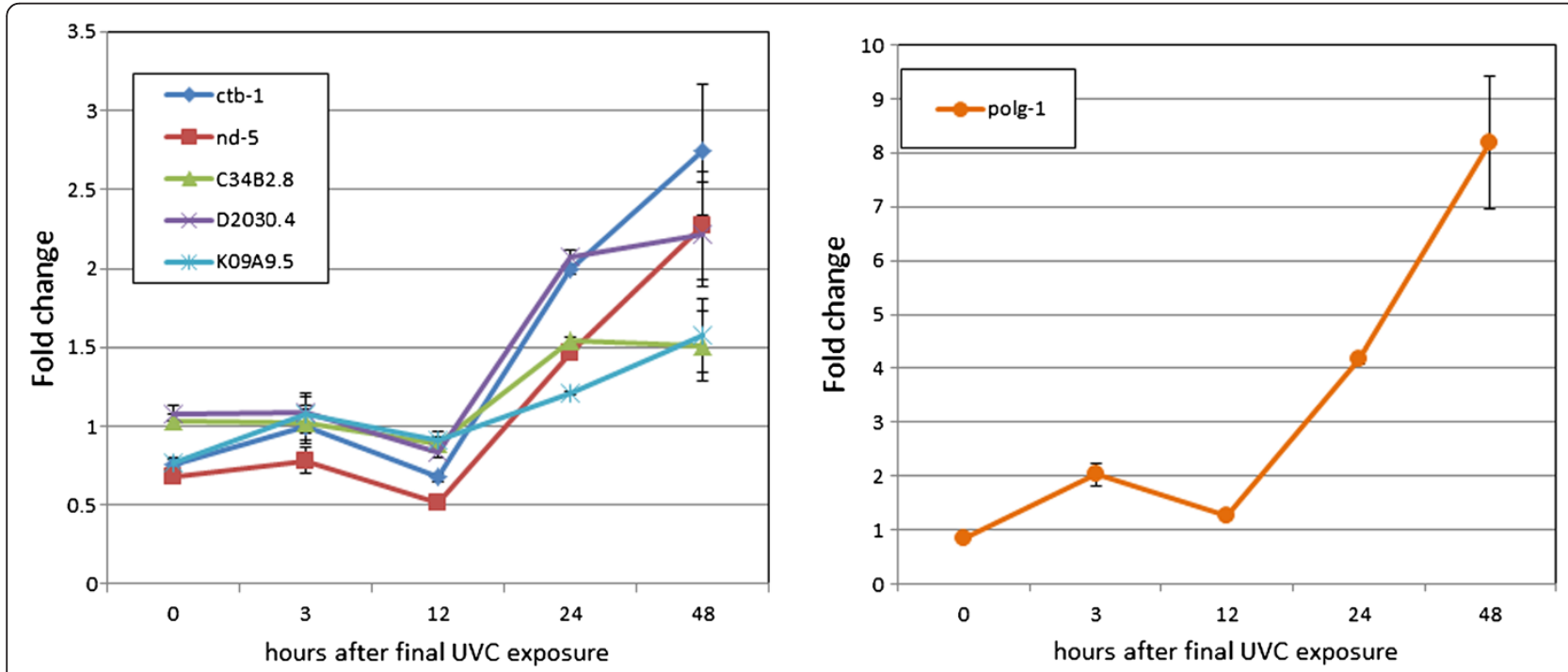

Figure 6 Exposure to UVC reduced $c t b-1$ and $n d-5$ expression at early timepoints, but resulted in higher levels of all mRNAs at later times (wild-type N2 strain). ctb-1 and nd-5 are mtDNA-encoded, and C34B2.8, D2030.4, K09A9.5, polg-1 are nDNA-encoded, mitochondrial proteins. polg-1 is graphed separately to avoid obscuring the smaller fold-changes observed in the other genes; note different $y$-axes. $p<0.0001$ for all main and interactive effects, 3 factor ANOVA. Fold change is relative to the mRNA of the same gene at the same time without UVC exposure. $n=3-6$. 


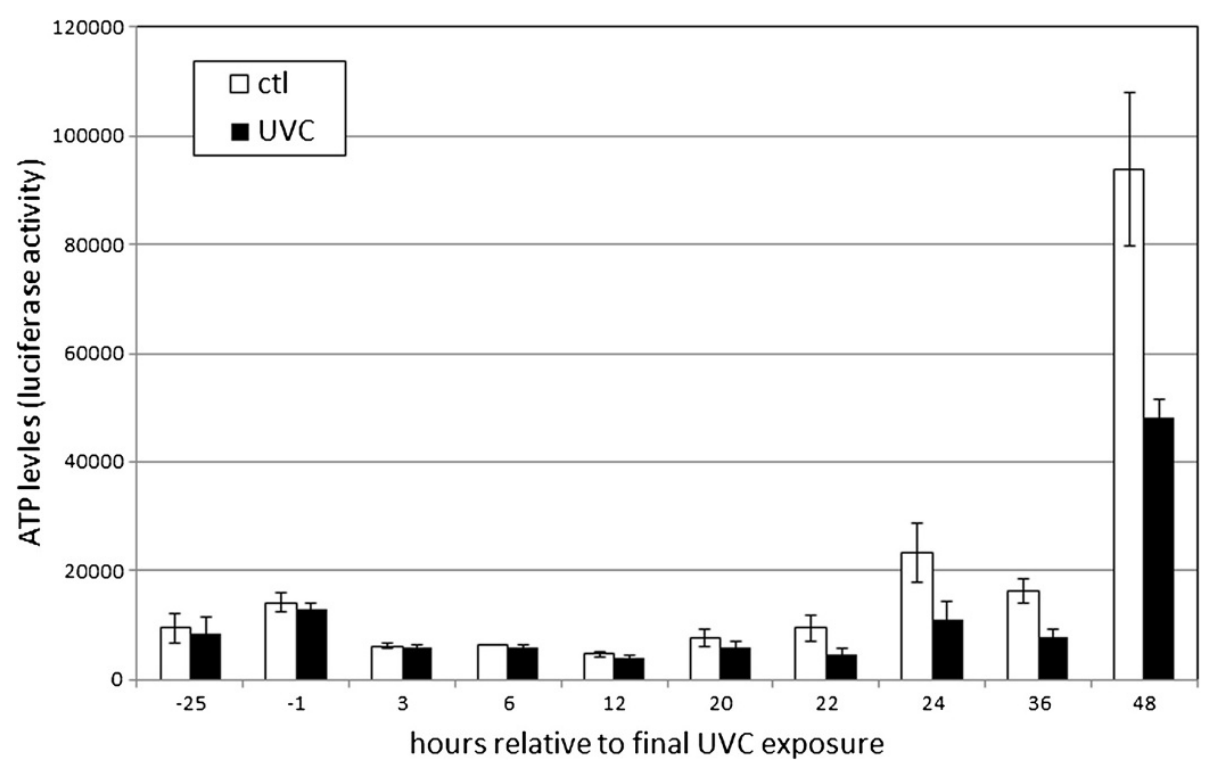

Figure 7 Exposure to UVC reduced ATP levels at later larval stages in developing $C$. elegans. The main effects of UVC and time were significant $(p=0.003$ and $p<0.0001$ respectively), but their interaction was not, precluding comparisons at specific timepoints. $n=5-7$ separate experiments; 5 separate measurements per experiment were pooled for each " $n$ ".

$48 \mathrm{~h}$ post-exposure, when ATP levels were rising significantly (Figure 7$)(\mathrm{p}=0.003$ and $\mathrm{p}<0.0001$ for main effects of UVC and time).

UVC exposure resulted in decreased oxygen consumption Since ATP can also be produced anaerobically and is a function of both production and use, steady-state ATP levels are an indirect readout of oxidative phosphorylation

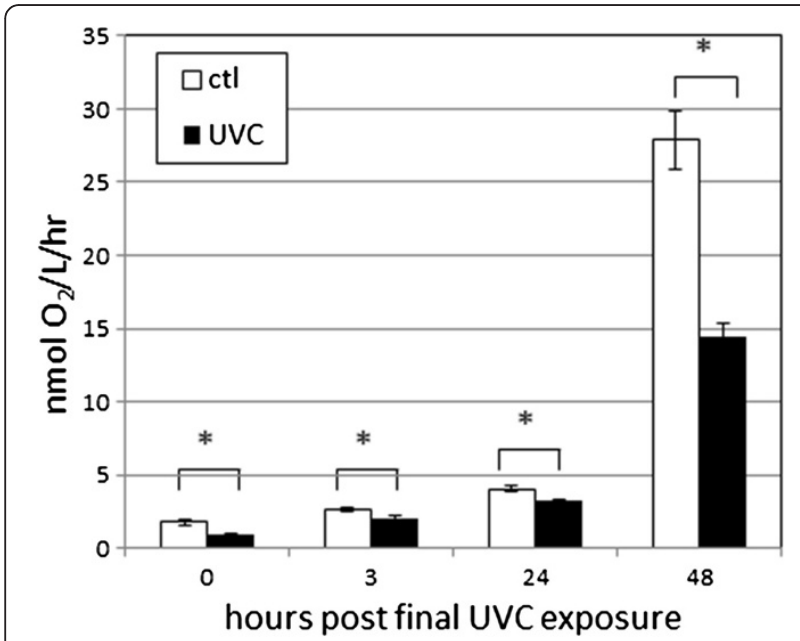

Figure 8 Exposure to UVC reduced oxygen consumption in larval C. elegans. $n=4-6$ in 3 experiments. The effects of time and UVC and their interactions were all significant at $p<0.0001$ (ANOVA); all FPLSD comparisons for the effect of UVC at individual timepoints were significant at $p \leq 0.001$ (indicated by asterisks). function. Therefore, to complement the ATP data, we also measured oxygen consumption in PE255 nematodes. Oxygen consumption, unlike ATP levels, did not drop between 0 and 3 h post-exposure (Figure 8 ), suggesting that the drop in ATP after addition of food resulted from a higher flux of ATP rather than an overall decrease in energy production. Consistent with previous research [44], we observed a strong increase in oxygen consumption during larval development. The UVC exposure resulted in a statistically significant ( $\mathrm{p} \leq 0.001$, FPLSD) decrease in oxygen consumption at all timepoints. However, the degree of decrease varied ( $\mathrm{p}<0.0001$ for time $\mathrm{x}$ treatment interaction, ANOVA): $~ 50 \%$ decrease at 0 and $48 \mathrm{~h}$ post-exposure, but $\sim 20 \%$ at 3 and $24 \mathrm{~h}$ (Figure 8 ).

\section{Discussion}

Previous work has demonstrated that mtDNA damage generated by exposure to alkylating and oxidative agents can cause mitochondrial dysfunction in a cell culture system [14]. However, such damage is generally repairable in mtDNA $[3,45]$. In contrast, UVC-induced DNA damage is not repaired in mtDNA in C. elegans [19], although it can be slowly removed [15]. Here, we report on the effect of a serial UVC exposure, which results in highly persistent mtDNA damage, on genome-level transcription and mitochondrial function.

The strong overall effect of time on our transcriptomic profiles is not surprising, since the transcriptomic response to starvation in L1s is established within $6 \mathrm{~h}$, and the response to food addition is established even more 
quickly (by $3 \mathrm{~h}$ ) due to RNA polymerase II accumulation in the promoters of growth-related genes [46]. However, we were surprised not to observe a strong mitochondriarelated transcriptomic response to serial UVC alone or in combination with the mtDNA intercalator $\mathrm{EtBr}$. At the timepoints examined, the transcriptomic response to persistent mtDNA damage (from the UVC) and inhibition of mtDNA replication (from the $\mathrm{EtBr}$ ) was mild and not very different than $\mathrm{EtBr}$ alone. Taken together, these results suggest that $C$. elegans lacks a way to specifically identify and respond transcriptionally to mtDNA damage, that this response is inactive at that time in development, or that any such response is very limited.

Although the transcriptomic response to $\mathrm{EtBr}$ by itself was quite robust, it did not include genes that are obviously related to mtDNA maintenance. Rather, the response was dominated by induction of "xenobiotic metabolism" (including cellular efflux pumps) as well as nuclear hormone receptor genes. The category of "xenobiotic metabolism," however, should be treated with caution since the actual substrate specificity of the corresponding enzymes has generally not been tested. Nonetheless, the degree of induction is remarkable, and adds to the growing literature on the ability of this nematode to transcriptionally modulate the metabolic response to xenobiotics [47-49].

UVC, EtBr, and the combination acted to inhibit development-related transcriptomic changes associated with food addition, and also altered the mRNA levels for genes involved in energy metabolism both during starvation and after food addition. This is consistent with the induction of glycolysis genes in human cells depleted of mtDNA [50]. It is also consistent with our other results that showed decreased ATP levels, oxygen consumption, and mtDNA copy number, since all of these typically increase during development. We note that we measured ATP levels and oxygen consumption only in PE255 nematodes, and the difference in UVCinduced mRNA levels indicates a need for caution in extrapolating results between PE255 and N2 nematodes. However, the developmental patterns that we observed were similar to those previously published for N2 nematodes, suggesting that overall mitochondrial function is likely similar in N2 and PE255 nematodes.

It is interesting that the observed decreases in mitochondrial function were not associated with a decrease in nDNA copy number. This suggests that development itself, as measured by cell division (which occurs according to an invariant pattern in C. elegans), was not significantly hindered. This conclusion is also supported by our previous observation of only a very slight delay in development at this dose of serial UVC [15]. This is surprising given the documented ability of mitochondrial dysfunction to inhibit larval development in C. elegans $[9,51,52]$. We propose two possibilities to explain this: first, as suggested by previous work, that the developmental delay results not so much from mitochondrial dysfunction per se, but rather from a signaling event that presumably was not activated at this level of damage $[52,53]$; second, that the threshold of mitochondrial dysfunction required to hinder development was not reached. These hypotheses, as well as an exploration of effects in adults, are important areas of future research.

We hypothesized that since the DNA damage was repaired in nDNA but not mtDNA, transcription of ETC components would be imbalanced, resulting in mitochondrial dysfunction. While the decreases in mRNA levels that we observed at early times were not enormous (maximally $50 \%$ ), we note that in human cells, mtRNA represents between $5 \%$ and $30 \%$ of total cellular RNA [54], suggesting that production of high levels is important. However, there was no induction of $h s p-6$ and $h s p-60$, which respond to imbalance of ETC proteins [55]. This suggests the possibility of retrograde signaling that permits the organism to maintain an appropriate balance of ETC proteins. Similarly, there was not a strong transcriptomic signature indicative of oxidative stress (e.g., induction of gst-4 or gcs-1: [56,57]), as might be expected if there were significant ETC dysfunction [58]. The lack of induction of these and other common general stress-response pathways also suggests that, although UVC is not entirely specific for nucleic acids, damage to other cellular macromolecules was not widespread. Overall, the relatively mild response to persistent mtDNA damage suggests that $C$. elegans has a significant ability to maintain mitochondrial function despite such damage, as we recently observed is true for primary human fibroblasts [59].

The significant induction in polg-1 and ETC mRNAs at 24 and $48 \mathrm{~h}$ post-exposure may also explain in part the nematodes' ability to recover from damage, and to begin replenishing the mtDNA population by $48 \mathrm{~h}$. It may be that polg-1 was not induced at early timepoints because of the relatively low dependence on mitochondrial function exhibited by $C$. elegans at those developmental stages. That insensitivity has been previously demonstrated by studies showing that mitochondrial dysfunction results in developmental arrest at the L3 or L4 stage, not earlier $[9,51,52]$, and that $C$. elegans lacking both copies of polg-1 are able to survive to late larval stages and even in some cases early adulthood [28]. Similarly, the induction of ETC genes supports an adaptive response, and is consistent with the ability to tolerate and transcriptionally compensate for mtDNA depletion previously observed in HeLa cells [60].

A fuller understanding of the basic biology of mtDNA maintenance in $C$. elegans will help elucidate a more complete understanding of the replicative and transcriptional response to such damage in this organism. Mitochondrial biogenesis is an important response to 
mitochondrial stress or dysfunction in mammalian cells [61], and our mRNA induction data supports such a response in C. elegans. However, mitochondrial biogenesis per se has not been described in C. elegans. In addition, although there are many similarities with mammalian mtDNA, there are also differences. For example, TFAM has not been found in C. elegans-perhaps because if present, it may not have a transcriptional role, as appears to be the case in yeast [62]. It is also interesting that in C. elegans there are apparently no genes on the light strand, raising questions about how transcription and replication are coupled in this species, since light strand transcription is the mechanism for priming mtDNA replication in humans $[63,64]$.

\section{Conclusions}

In summary, our results support the hypothesis that early life exposure to persistent mtDNA damage can lead to later life mitochondrial dysfunction. However, they also highlight the ability to compensate for or respond to such damage in vivo. Some of this capacity is likely the result of the ability to clear such damage via mitochondrial dynamics and autophagy [15]. An important direction of future research will be to investigate how deficiencies in those processeswhich are observed in the human population-will affect the response to such damage.

\section{Additional files}

Additional file 1: Figure 1. The C. elegans mitochondrial genome, produced with Organellar GenomeDraw (Lohse et al., 2007). The blue arrow indicates the direction of transcription (Okimoto et al., 1992). mRNA levels of the two genes highlighted in purple were measured using RT-PCR. Figure 2. Exposure to $\mathrm{EtBr}(5 \mu \mathrm{g} / \mathrm{mL})$ did not result in measureable DNA damage (measured $1 \mathrm{~h}$ after the third UVC exposure) in either genome, nor did it exacerbate UVC-induced DNA damage in either genome ( $p>0.05$ for main effect of EtBr and interaction term, 2 factor ANOVA). The exposures did not result in a marked change in mtDNA:nDNA ratio (bottom panel); time $(p=0.50)$, treatment $(p=0.91)$ and the interaction term $(p=0.89)$ were all statistically insignificant. Therefore, we could not make direct within-time comparisons by FPLSD. $\mathrm{n}=4-8$ per bar. Figure 3. Time and $\mathrm{EtBr}$ were the major drivers of differential gene expression by ANOVA and PCA. Even at the least stringent $p$-value, where 748 differentially expressed genes are expected to be identified by chance, no genes were differentially regulated in response to UVC in a way that was modulated by $\mathrm{EtBr}$ or $\mathrm{EtBr}$ and time. In the PCA (three views of same plot), the $x$-axis (component 1) explains $52 \%$ of variability, the $y$-axis $21 \%$, and the $z$-axis $14 \%$. Blue indicates $-45 h$, red $-25 \mathrm{~h}$, maroon $-1 \mathrm{~h}$, and grey $3 \mathrm{~h}$. Diamonds indicate control samples, circles UVC, squares EtBr, and triangles UVC + EtBr. Analyses performed with GeneSpring. Figure 4. At $3 \mathrm{~h}$, the combination treatment led to additional effects compared to EtBr alone. Development is the mostaltered gene ontology; differences were also observed in transcription, protein catabolism, and organellar organization. Blue indicates higher expression in the combination than in $\mathrm{EtBr}$ alone. Figure 5. Some autophagy genes were induced by EtBr and UVC at later timepoints (top panel; lgg-2 highlighted). No changes were observed in fusion or fission genes (bottom panel; eat-3 highlighted). Red-blue scale coloration is based on comparison to mRNA levels in control samples at $-45 \mathrm{~h}$. Normalized intensity values are on a binary log scale (i.e. "1" indicates a 2-fold change, "2" a 4- fold change, ETC). $n=4$-6. Figure 6. Many cytochrome P450 genes were upregulated by exposure to ethidium bromide; shown are genes upregulated by EtBr and fitting the $\mathrm{GO}$ term "monoxygenase activity." The genes shown are cyp-35B3 (highlighted in green), cyp-13A7, сур-35A5, cyp-35B1, сур- 33C3, сур-33С6, сур-33C7, сур33D3, cyp-35B2, cyp-35A1, cyp-33C5, and cyp-33C4. Red-blue scale coloration is based on comparison to mRNA levels in control samples at $-45 \mathrm{~h}$. Normalized intensity values are on a binary log scale (i.e. "1" indicates a 2-fold change, "2" a 4-fold change, ETC). $n=4-6$. Figure 7. There is little change in expression of known DNA repair genes (from Boyd et al., 2010) either with time or treatment, with the exception of pme-4 (highlighted). Red-blue scale coloration is based on comparison to mRNA levels in control samples at $-45 \mathrm{~h}$. Normalized intensity values are on a binary log scale (i.e. "1" indicates a 2-fold change, "2" a 4-fold change, ETC). $n=4-6$. Figure 8. Effect of exposure to UVC, EtBr or both on mRNA levels for mtDNA-encoded ( $c t b-1$, nd-5) and nDNA-encoded (C34B2.8, D2030.4, K09A9.5, polg-1) mitochondrial proteins. The legend is the same for all graphs. $p<0.05$ for main effects of time, treatment, and genome, and genome $x$ time interactions. Fold change is relative to the mRNA of the same gene at the same time without UVC exposure. $n=5-7$ (samples derived from microarray experiment exposures, including additional samples not used for microarray). Figure 9. Effects of exposure to UVC in the PE255 strain. polg-1 is graphed separately for consistency with Figure 6. ctb-1 and nd-5 are mtDNA-encoded, and C34B2.8, D2030.4, K09A9.5, polg-1 are nDNA-encoded, mitochondrial proteins. The effect of UVC and gene ( $p=0.016$ and $p<0.0001$ respectively) were significant, as was the interaction of UVC with gene $(p=0.003)$. No other main or interactive effects were significant ( $p>0.05,3$ factor ANOVA). Comparisons at specific times could not be made due to the lack of significant interactions involving time. Gene-by-gene comparisons (across time) by FPLSD indicated that polg- 1 behaved differently than all other genes ( $p \leq 0.003)$, and $n d-5$ was distinct from K09A9.5 $(p=0.02)$. Fold change is relative to the mRNA of the same gene at the same time without UVC exposure $n=3-6$.

Additional file 2: This file contains the "Union4" interactome described in the text (Methods section), containing 14334 nodes and 346484 edges. It is in the Cytoscape-compatible .sif file format. Additional file 3: This file contains differentially expressed transcripts (defined as fold-change $>1.2, p<0.05$ based on Rosetta Resolver analysis) for all pairwise treatment comparisons at the $3 \mathrm{~h}$ timepoint.

\section{Competing interests}

The authors declare that they have no competing interests.

\section{Authors' contributions}

MCKL, JPR, ITR, ASB, and AQJ carried out measurements of mtDNA damage, mtDNA and nDNA copy number, mRNA levels by RT-PCR, oxygen consumption, and ATP levels. AJB and TLC carried out microarray experiments. MCKL, JPR and JNM participated in study design and coordination; MCKL and JNM drafted the manuscript. All authors read and approved the final manuscript.

\section{Acknowledgements}

We thank Marni Falk for primer information, Alexandra Trifunovic for a plasmid-based mtDNA copy number standard curve, and Bernard Lemire for advice regarding oxygen consumption measurement. We thank Margaret Gustafson, Shawn Ahmed, and Jonathan Freedman for their advice and assistance in this study. This work was funded by NIEHS and NINDS (1P30 ES011961, 1R01-ES017540, and 1R21 NS065468 to JNM), the Society of Toxicology (Colgate-Palmolive Awards for Student Research Training in Alternative Methods to MCKL); American Foundation of Aging Research (GlaxoSmithKline Foundation Award to MCKL).

Received: 24 September 2012 Accepted: 14 January 2013 Published: 4 February 2013

\section{References}

1. Schmidt CW: Mito-conundrum unraveling environmental effects on mitochondria. Environ Heal Perspect 2010, 118:A292-A297. 
2. Shaughnessy DT, Worth L, Lawler CP, McAllister KA, Longley MJ, Copeland WC: Meeting report: Identification of biomarkers for early detection of mitochondrial dysfunction. Mitochondrion 2010, 10:579-581.

3. Larsen NB, Rasmussen M, Rasmussen LJ: Nuclear and mitochondrial DNA repair: similar pathways? Mitochondrion 2005, 5:89-108.

4. Cohen BH: Pharmacologic effects on mitochondrial function. Dev Disabil Res Rev 2010, 16:189-199.

5. Gomez C, Bandez MJ, Navarro A: Pesticides and impairment of mitochondrial function in relation with the parkinsonian syndrome. Front Biosci 2007 12:1079-1093.

6. Benhammou V, Tardieu M, Warszawski J, Rustin P, Blanche S: Clinical mitochondrial dysfunction in uninfected children born to HIV-infected mothers following perinatal exposure to nucleoside analogues. Environ Mol Mutagen 2007, 48:173-178.

7. Tsang WY, Lemire BD: The role of mitochondria in the life of the nematode Caenorhabditis elegans. Biochim Biophys Acta 2003, 1638:91-105.

8. Breton S, Stewart DT, Hoeh WR: Characterization of a mitochondria ORF from the gender-associated mtDNAs of Mytilus spp. (Bivalvia: Mytilidae): Identification of the "missing" ATPase 8 gene. Mar Genom 2010, 3:11-18.

9. Tsang WY, Lemire BD: Mitochondrial genome content is regulated during nematode development. Biochem Biophys Res Commun 2002, 291:8-16.

10. Braeckman BP, Houthoofd K, Vanfleteren JR: Intermediary metabolism. WormBook 2009, doi:10.1895/wormbook.1.146.1.

11. May-Panloup P, Chretien MF, Malthiery $Y$, Reynier P: Mitochondrial DNA in the oocyte and the developing embryo. Curr Top Dev Biol 2007, 77:51-83.

12. Shoubridge EA: Mitochondrial DNA segregation in the developing embryo. Hum Reprod 2000, 15(Suppl 2):229-234.

13. Leung MC-K, Williams PL, Benedetto A, Au C, Helmke KJ, Aschner M, Meyer $\mathrm{JN}$ : Caenorhabditis elegans: an emerging model in biomedical and environmental toxicology. Toxicol Sci 2008, 106:5-28.

14. Furda AM, Marrangoni AM, Lokshin A, Van Houten B: Oxidants and not alkylating agents induce rapid mtDNA loss and mitochondrial dysfunction. DNA Repair (Amst) 2012, 11:684-692

15. Bess AS, Crocker TL, Ryde IT, Meyer JN: Mitochondrial dynamics and autophagy aid in removal of persistent mitochondrial DNA damage in Caenorhabditis elegans. Nucleic Acids Res 2012, 40:7916-7931.

16. Kasiviswanathan R, Gustafson MA, Copeland WC, Meyer JN: Human mitochondrial DNA polymerase gamma exhibits potential for bypass and mutagenesis at UV-induced cyclobutane thymine dimers. J Biol Chem 2012, 287:9222-9229.

17. Cline SD: Mitochondrial DNA damage and its consequences for mitochondrial gene expression. Biochim Biophys Acta 2012, 1819:979-991.

18. Lewis JA, Fleming JT: Basic Culture Methods. In Caenorhabditis elegans: Modern Biological Analysis of an Organism. Edited by Epstein HF, Shakes DC. San Digo, CA: Academic Press; 1995:3-29.

19. Meyer JN, Boyd WA, Azzam GA, Haugen AC, Freedman JH, Van Houten B: Decline of nucleotide excision repair capacity in aging Caenorhabditis elegans. Genome Biol 2007, 8:R70.

20. Lagido C, Pettitt J, Flett A, Glover LA: Bridging the phenotypic gap: realtime assessment of mitochondrial function and metabolism of the nematode Caenorhabditis elegans. BMC Physiol 2008, 8:7.

21. Simonis N, Rual JF, Carvunis AR, Tasan M, Lemmens I, Hirozane-Kishikawa T, Hao T, Sahalie JM, Venkatesan K, Gebreab F, et al: Empirically controlled mapping of the Caenorhabditis elegans protein-protein interactome network. Nat Methods 2009, 6:47-54.

22. Alfarano C, Andrade CE, Anthony K, Bahroos N, Bajec M, Bantoft K, Betel D, Bobechko B, Boutilier K, Burgess E, et al: The biomolecular interaction network database and related tools 2005 update. Nucleic Acids Res 2005, 33:D418-424.

23. Zhong W, Sternberg PW: Genome-wide prediction of $C$. elegans genetic interactions. Science 2006, 311:1481-1484.

24. Lee I, Lehner B, Crombie C, Wong W, Fraser AG, Marcotte EM: A single gene network accurately predicts phenotypic effects of gene perturbation in Caenorhabditis elegans. Nat Genet 2008, 40:181-188.

25. Alexeyenko A, Sonnhammer EL: Global networks of functional coupling in eukaryotes from comprehensive data integration. Genome Res 2009, 19:1107-1116.

26. Ideker T, Ozier O, Schwikowski B, Siegel AF: Discovering regulatory and signalling circuits in molecular interaction networks. Bioinformatics 2002, 18(Suppl 1):S233-240.
27. Maere S, Heymans K, Kuiper M: BiNGO: a Cytoscape plugin to assess overrepresentation of gene ontology categories in biological networks. Bioinformatics 2005, 21:3448-3449.

28. Bratic I, Hench J, Henriksson J, Antebi A, Burglin TR, Trifunovic A Mitochondrial DNA level, but not active replicase, is essential for Caenorhabditis elegans development. Nucleic Acids Res 2009, 37:1817-1828

29. Rozen S, Skaletsky H: Primer3 on the WWW for general users and for biologist programmers. Methods Mol Biol 2000, 132:365-386.

30. Kodoyianni V, Maine EM, Kimble J: Molecular basis of loss-of-function mutations in the glp-1 gene of Caenorhabitis elegans. Mol Biol Cell 1992, 3:1199-1213.

31. Sulston J: Cell Lineage. In The Nematode Caenorhabditis elegans. Edited by Wood WB. Cold Spring Harbor, NY: Cold Spring Harbor Laboratory Press; 1988:123-155.

32. Golden TR, Beckman KB, Lee AH, Dudek N, Hubbard A, Samper E, Melov S: Dramatic age-related changes in nuclear and genome copy number in the nematode Caenorhabditis elegans. Aging Cell 2007, 6:179-188.

33. Emmons SW: The Genome. In The Nematode Caenorhabditis elegans. Edited by Wood WB. Cold Spring Harbor, NY: Cold Spring Harbor Laboratory Press; 1988:47-79

34. Boyd WA, Crocker TL, Rodriguez AM, Leung MC, Lehmann DW, Freedman $\mathrm{JH}$, Van Houten B, Meyer JN: Nucleotide excision repair genes are expressed at low levels and are not detectably inducible in Caenorhabditis elegans somatic tissues, but their function is required for normal adult life after UVC exposure. Mutat Res 2010, 683:57-67.

35. Hunter S, Jung D, Di Giulio R, Meyer J: The QPCR assay for analysis of mitochondrial DNA damage, repair, and relative copy number. Methods 2010, 51:444-451.

36. Hoogewijs D, Houthoofd K, Matthijssens F, Vandesompele J, Vanfleteren JR: Selection and validation of a set of reliable reference genes for quantitative sod gene expression analysis in C. elegans. BMC Mol Biol 2008, 9:9.

37. McLaggan D, Amezaga MR, Petra E, Frost A, Duff El, Rhind SM, Fowler PA, Glover LA, Lagido C: Impact of sublethal levels of environmental pollutants found in sewage sluge on a novel Caenorhabditis elegans model biosensor. PLoS One 2012, 7(10):e46503.

38. Grad LI, Sayles LC, Lemire BD: Isolation and functional analysis of mitochondria from the nematode Caenorhabditis elegans. Methods $\mathrm{Mol}$ Biol 2007, 372:51-66.

39. Gaines G, Attardi G: Intercalating drugs and low temperatures inhibit synthesis and processing of ribosomal RNA in isolated human mitochondria. J Mol Biol 1984, 172:451-466.

40. Hall DB, Kelley SO, Barton JK: Long-range and short-range oxidative damage to DNA: photoinduced damage to guanines in ethidium-DNA assemblies. Biochemistry 1998, 37:15933-15940.

41. Kurbanyan K, Nguyen KL, To P, Rivas EV, Lueras AM, Kosinski C, Steryo M, Gonzalez A, Mah DA, Stemp ED: DNA-protein cross-linking via guanine oxidation: dependence upon protein and photosensitizer. Biochemistry 2003, 42:10269-10281.

42. Ichishita R, Tanaka K, Sugiura Y, Sayano T, Mihara K, Oka T: An RNAi screen for mitochondrial proteins required to maintain the morphology of the organelle in Caenorhabditis elegans. J Biochem 2008, 143:449-454.

43. Lagido C, McLaggan D, Flett A, Pettitt J, Glover LA: Rapid sublethal toxicity assessment using bioluminescent Caenorhabditis elegans, a novel wholeanimal metabolic biosensor. Toxicol Sci 2009, 109:88-95.

44. Houthoofd K, Braeckman BP, Lenaerts I, Brys K, De Vreese A, Van Eygen S, Vanfleteren JR: Ageing is reversed, and metabolism is reset to young levels in recovering dauer larvae of C. elegans. Exp Gerontol 2002, 37:1015-1021.

45. Hunter SE, Gustafson MA, Margillo KM, Lee SA, Ryde IT, Meyer JN: In vivo repair of alkylating and oxidative DNA damage in the mitochondrial and nuclear genomes of wild-type and glycosylase-deficient Caenorhabditis elegans. DNA Repair (Amst) 2012, 11:857-863.

46. Baugh LR, Demodena J, Sternberg PW: RNA Pol II accumulates at promoters of growth genes during developmental arrest. Science 2009, 324:92-94.

47. Menzel R, Bogaert T, Achazi R: A systematic gene expression screen of Caenorhabditis elegans cytochrome P450 genes reveals CYP35 as strongly xenobiotic inducible. Arch Biochem Biophys 2001, 395:158-168.

48. Menzel R, Rodel M, Kulas J, Steinberg CE: CYP35: xenobiotically induced gene expression in the nematode Caenorhabditis elegans. Arch Biochem Biophys 2005, 438:93-102.

49. Lindblom TH, Dodd AK: Xenobiotic detoxification in the nematode Caenorhabditis elegans. J Exp Zool 2006, 305:720-730. 
50. Behan A, Doyle S, Farrell M: Adaptive responses to mitochondrial dysfunction in the rho degrees Namalwa cell. Mitochondrion 2005, 5:173-193.

51. Tsang WY, Sayles LC, Grad LI, Pilgrim DB, Lemire BD: Mitochondrial respiratory chain deficiency in Caenorhabditis elegans results in developmental arrest and increased life span. J Biol Chem 2001, 276:32240-32246.

52. Ventura N, Rea SL, Schiavi A, Torgovnick A, Testi R, Johnson TE: p53/CEP-1 increases or decreases lifespan, depending on level of mitochondrial bioenergetic stress. Aging Cell 2009, 8:380-393.

53. Torgovnick A, Schiavi A, Testi R, Ventura N: A role for $\mathrm{p} 53$ in mitochondrial stress response control of longevity in C. elegans. Exp Gerontol 2010, 45:550-557.

54. Mercer TR, Neph S, Dinger ME, Crawford J, Smith MA, Shearwood AM, Haugen E, Bracken CP, Rackham O, Stamatoyannopoulos JA, et al: The human mitochondrial transcriptome. Cell 2011, 146:645-658.

55. Durieux J, Wolff S, Dillin A: The cell-non-autonomous nature of electron transport chain-mediated longevity. Cell 2011, 144:79-91.

56. An JH, Blackwell TK: SKN-1 links C. elegans mesendodermal specification to a conserved oxidative stress response. Genes Dev 2003, 17:1882-1893.

57. Kahn NW, Rea SL, Moyle S, Kell A, Johnson TE: Proteasomal dysfunction activates the transcription factor $\mathrm{SKN}-1$ and produces a selective oxidative-stress response in Caenorhabditis elegans. Biochem J 2008, 409:205-213.

58. Dingley S, Polyak E, Lightfoot R, Ostrovsky J, Rao M, Greco T, Ischiropoulos $H$, Falk MJ: Mitochondrial respiratory chain dysfunction variably increases oxidant stress in Caenorhabditis elegans. Mitochondrion 2010, 10:125-136.

59. Bess AS, Ryde IT, Hinton DE, Meyer JN: UVC-induced mitochondrial degradation via autophagy correlates with mtDNA damage removal in primary human fibroblasts. J Biochem Mol Toxicol. 2013, 27:28-41.

60. Piechota J, Szczesny R, Wolanin K, Chlebowski A, Bartnik E: Nuclear and mitochondrial genome responses in HeLa cells treated with inhibitors of mitochondrial DNA expression. Acta Biochim Pol 2006, 53:485-495.

61. Scarpulla RC: Nucleus-encoded regulators of mitochondrial function: Integration of respiratory chain expression, nutrient sensing and metabolic stress. Biochim Biophys Acta 2012, 1819:1088-1097.

62. Shutt TE, Lodeiro MF, Cotney J, Cameron CE, Shadel GS: Core human mitochondrial transcription apparatus is a regulated two-component system in vitro. Proc Natl Acad Sci USA 2010, 107:12133-12138.

63. Chang DD, Clayton DA: Priming of human mitochondrial DNA replication occurs at the light-strand promoter. Proc Natl Acad Sci USA 1985, 82:351-355.

64. Kasiviswanathan R, Collins TR, Copeland WC: The interface of transcription and DNA replication in the mitochondria. Biochim Biophys Acta 2012, 1819:970-978.

doi:10.1186/2050-6511-14-9

Cite this article as: Leung et al:: Effects of early life exposure to ultraviolet $\mathrm{C}$ radiation on mitochondrial DNA content, transcription, ATP production, and oxygen consumption in developing Caenorhabditis elegans. BMC Pharmacology and Toxicology 2013 14:9.

\section{Submit your next manuscript to BioMed Central and take full advantage of:}

- Convenient online submission

- Thorough peer review

- No space constraints or color figure charges

- Immediate publication on acceptance

- Inclusion in PubMed, CAS, Scopus and Google Scholar

- Research which is freely available for redistribution

Submit your manuscript at www.biomedcentral.com/submit
( Biomed Central 